\title{
Evaluation of prevalence of Candida species in the root canals and oral cavity of children and adult patients.
}

\author{
Avneet Kaur ${ }^{1}$, Puneet Singh Soodan ${ }^{2}$, Kanwaldeep Singh Soodan ${ }^{3}$, \\ Pratiksha Priyadarshni ${ }^{4}$ \\ ${ }^{I}$ (Department of Microbiology, M.M.Institute of Medical Sciences and Research , Mullana, Ambala/Maharishi \\ Markandeshwar University, India) \\ ${ }_{2}^{2}$ (Department of Dermatology, Shri Ram Murti Smarak institute of Medical Sciences, Barielly (U.P)/Rohilkhand \\ University, India) \\ ${ }^{3}$ (Department of Oral \& Maxillofacial surgery, M.M.Institute of Medical Sciences and Research , Mullana, \\ Ambala/ Maharishi Markandeshwar University, India) \\ ${ }^{4}$ (Department of Oral \& Maxillofacial surgery, M.M.Institute of Medical Sciences and Research , Mullana, \\ Ambala/ Maharishi Markandeshwar University, India)
}

\begin{abstract}
:
Background: Fungi are oral commensal in about half of general population and its largest proportion is made up of Candida species. Candida causes wide variety of infections in human beings. Objectives: To evaluate the prevalence of Candida species in root canals and oral cavities of children and adults.

Material and methods: Swabs from oral cavities of 100 patients were collected and subjected to culture on Sabourad's dextrose agar and chromogenic Candida differential agar.

Results: Prevalence of oral candida in healthy children and adults belonging to control group was $8 \%$ and $4 \%$ respectively. Prevalence rate of Candida in root canals of children was 4 (16\%) and in adults $1(4 \%)$. Out of 50 samples collected from oral cavities of children, 6 (12\%) were positive for Candida comprising of 5(83\%) Candida albicans and 1(17\%) Candida tropicalis. From 50 adult subjects, only 2 samples were positive for Candida i.e 1(4\%) Candida parapsilosis and 1(4\%) Candida albicans.

Conclusion: Candida albicans was found to be the most common isolated species of Candida from the oral cavity in children with or without caries. Hence, presence of carious lesion has no effect on Candidial colonization of oral cavity in both children and adults.
\end{abstract}

Keywords: C.albicans- Candida albicans, C.parapsilosis- Candida parapsilosis, C.krusei- Candida krusei

\section{Introduction}

Fungi constitute a small part of the oral microbiota. ${ }^{1}$ More than 50,000 species of fungi exist, but only 100 to 150 are generally recognised as a cause of disease for humans. ${ }^{2}$ It is commonly detected in the oral cavity of both healthy and medically compromised individuals. Besides oral cavity, they are also carried in the gastrointestinal tract, anus, groin, vaginal canal and vulva of healthy individuals. ${ }^{1}$ The incidence of fungal infections has increased in recent decades in many countries, which has stimulated scientific studies.

The term Candida originates from the Latin word candid, meaning white. The spores of Candida are a commensal, harmless form of a dimorphic fungus that becomes invasive and pathogenic pseudohyphae when there is a disturbance in the balance of flora or in debilitation of the host. ${ }^{3}$ The Candida genus presents over 150 species of which 10 are responsible for infections in humans, of these, Candida albicans is part of its normal microbiota and is isolated in greatest frequency from the oral cavity in human beings. ${ }^{4}$ It is estimated that this species accounts for over $80 \%$ of all oral yeast isolates. ${ }^{3}$ Candida species are ubiquitous yeasts and common residents of mucosal surfaces of the human oral cavity, the gastrointestinal and the urogenital tract. Essentially all areas of the human gastrointestinal tract can harbor Candida. The most commonly isolated species (50 to $70 \%$ of yeast isolates) from the human gastrointestinal tract is Candida albicans, followed by $\mathrm{C}$. tropicalis, C. parapsilosis, and C. glabrata. ${ }^{5}$ Candida species can cause a wide variety of infections in human beings, ranging from superficial disease to life-threatening disseminated mycosis. ${ }^{6}$ Candida albicans is the fungal species most commonly detected in the oral cavity. The incidence of C.albicans in the oral cavity has been reported to be $30 \%$ to $45 \%$ in healthy adults and $95 \%$ in patients infected with Human immunodeficiency virus. ${ }^{1}$ Fungi have been commonly found in the root canals of obturated teeth in which treatment has failed. They have also been isolated from periradicular lesions refractory to endodontic treatment. C. albicans has been associated with cases of persistent root canal infections, because this yeast can be resistant to some intracanal medications . ${ }^{7}$ Dental caries is a chronic and multifactorial disease that, although avoidable, still represents an important problem in public health, since it affects approximately $90 \%$ of the population, mainly children and adolescents, 
compromising their quality of life development. ${ }^{8}$ The development of caries depends on the interaction of factors relating to the host, especially a diet rich in fermentable carbohydrates, and the presence of cariogenic microorganisms. ${ }^{9}$ Caries are caused by a highly specific and complex microbial process resulting from a nonspecific accumulation of acid-producing microorganisms on teeth. ${ }^{10}$ Candida albicans has been considered to be a dentinophilic microorganism because of its invasive affinity to dentin. This ability to colonize dentin and invade dentinal tubules, combined with its resistance to intracranial medicaments, may account for presence of C.albicans in persistent root canal infections. Hence, this study was done to assess the prevalence of common species of Candida in root canal and oral cavity of children and adult patients.

\section{Material and Methods}

This cross-sectional study was carried out during the period January 2013 to December 2013 at M. M. Institute of Medical Sciences and Research, Mullana. A total of 100 subjects were selected from whom microbiological samples were obtained. The study population was divided into two groups- first group included children in the age range of 6-9 years and second group included adults in the age range of 20-40 years. Each group was further subdivided into experimental and control groups with 25 subjects in each group. All participants in the control group were caries-free. The inclusion criteria taken into consideration for experimental group was presence of atleast two carious teeth including one which was indicative for endodontic treatment. The salivary $\mathrm{pH}$ of all the subjects was measured using $\mathrm{pH}$ paper and was found to be in the range of 6-7. Each patient was asked to open the mouth and sterilized cotton swab taken from sterile test tube was rolled over the dorsum of tongue. The swab was then transferred to the microbiology laboratory in sterile normal saline within $30 \mathrm{mins}$ to $24 \mathrm{hours}$. In experimental group, swab was taken from the tongue in the similar manner. Root canal sample was obtained immediately after access opening was done by placing an absorbent paper point into the root canal for 1 minute. The paper point was then put in sterile tube containing sterile normal saline. Both the samples were transferred to microbiology laboratory within $30 \mathrm{~min}$ to 24 hours where the samples were inoculated on the Sabourad's dextrose agar and incubated at $37^{\circ} \mathrm{C}$. The colonies were observed after 24 to 48 hours. Gram stained smears were prepared from cream coloured colonies seen on Sabourad's dextrose agar. Gram positive oval budding cells were identified as yeasts. Positive colonies were then subcultured on chromogenic Candida differential agar and incubated at $37^{\circ} \mathrm{C}$ for 24 hours. The different species of Candida were recognised on the basis of colour of the colonies. Germ tube test was done for the presence of Candida albicans.

\section{Results}

The study was conducted on 100 subjects in the department of Oral and Maxillofacial surgery, to evaluate the prevalence of Candida and its species in the oral cavities and root canals. The study population was divided into two groups- first group included children in the age range of 6-9 years and second group included adults in the age range of 20-40 years. Each group was further subdivided into experimental and control groups with 25 subjects in each group. All participants in the control group were caries-free. The inclusion criteria taken into consideration for experimental group was presence of atleast two carious teeth including one which was indicative for endodontic treatment. The salivary $\mathrm{pH}$ of all the subjects was measured using $\mathrm{pH}$ paper and was found to be in the range of 6-7.

Table 1: Distribution of samples according to gender

\begin{tabular}{|c|c|c|c|c|}
\hline Group & \multicolumn{2}{|c|}{ Control } & \multicolumn{2}{c|}{ Experimental } \\
\hline & Males & Females & Males & Females \\
\hline Children & 15 & 10 & 20 & 5 \\
\hline Adults & 10 & 15 & 11 & 14 \\
\hline Total & 25 & 25 & 31 & 19 \\
\hline
\end{tabular}

Table 1 shows the distribution of samples according to gender into experimental and control groups. A total of 25 males ( 15 children and 10 adults) and 25 females ( 10 children and 15 adults) were present in control group. A total of 31 males ( 20 children and 11 adults) and 19 females ( 5 children and 14 adults) were present in experimental group.

Table 2: Distribution of samples according to presence/absence of Candida

\begin{tabular}{|c|c|c|c|c|}
\hline SEX & Total samples & Candida positive & Candida negative & $\begin{array}{c}\text { Percentage (Candida } \\
\text { positive) }\end{array}$ \\
\hline MALES & 56 & 9 & 47 & 16.07 \\
\hline FEMALES & 44 & 4 & 40 & 9.09 \\
\hline
\end{tabular}

Table 2 shows prevalence of Candida among 100 subjects who participated in the present study. Of 56 samples of males, $9(16.07 \%)$ showed the presence of Candida and of 44 females, $4(9.09 \%)$ showed presence of Candida. 
Table 3: Comparison of prevalence of Candida in oral cavities between males and females

\begin{tabular}{|c|c|c|}
\hline Parameter/ Group & Chi square & P value \\
\hline Males- females & 0.53 & 0.465 \\
\hline
\end{tabular}

Table 3 Compares the prevalence of Candida in oral cavities between males and females and the difference between two groups was statistically non-significant.

Table 4: Prevalence of Candida in oral cavities of different groups

\begin{tabular}{|c|c|c|c|c|c|}
\hline \multicolumn{2}{|c|}{ Group } & $\begin{array}{c}\text { No of subject } \\
\text { examined }\end{array}$ & Candida positive & Candida negative & $\begin{array}{c}\text { Percentage } \\
\text { (candida positive) }\end{array}$ \\
\hline \multirow{2}{*}{ CHILDREN } & Control & 25 & 2 & 23 & $8 \%$ \\
\cline { 2 - 6 } & Experimental & 25 & 4 & 21 & 24 \\
4 \\
\cline { 2 - 6 }
\end{tabular}

Table 4 shows the prevalence of Candida in oral cavities of children and adults. Out of 25 children in experimental group, $4(16 \%)$ tested positive for Candida whereas in control only 2 samples $(8 \%)$ were positive. Amongst the adults, 1 (4\%) sample was positive for Candida in the experimental group and 1 sample (4\%) was positive in the control group.

Table 5: Comparison of prevalence of Candida in oral cavities between experimental and control groups

\begin{tabular}{|c|c|}
\hline Parameter/Group & p value \\
\hline Children ( Experimental-Control) & 0.667 \\
\hline Adults (Experimental-control) & 1 \\
\hline
\end{tabular}

Table 5 compares the prevalence of Candida in oral cavities between experimental and control groups in both children and adults. The p-value for difference amongst the two groups of children was calculated to be 0.667 which was statistically non-significant. The $\mathrm{p}$-value for difference amongst the two groups of adults was 1 which was also statistically non-significant.

Table 6: Prevalence of Candida in Root canals of the two experimental groups

\begin{tabular}{|c|c|c|c|c|}
\hline Group & Examined & Candida positive & Candida negative & $\begin{array}{c}\text { Percentage (Candida } \\
\text { positive) }\end{array}$ \\
\hline CHILDREN & 25 & 4 & 21 & $16 \%$ \\
\hline ADULTS & 25 & 1 & 24 & $4 \%$ \\
\hline
\end{tabular}

Table 6 shows prevalence of Candida in Root canals of the two experimental groups. 25 root canal samples were obtained for microbiological examination in each group. Amongst adults, only 1 sample (4\%) tested positive for candida and in children 4 samples (16\%) were positive.

Table 7: Candida positive samples in root canals and oral cavity in experimental groups

\begin{tabular}{|c|c|c|c|}
\hline Group & Oral cavity & Root canals & Percentage \\
\hline Children $(\mathrm{n}=25)$ & 4 & 4 & $16 \%$ \\
\hline Adults $(\mathrm{n}=25)$ & 1 & 1 & $4 \%$ \\
\hline
\end{tabular}

Table 7 shows Candida positive samples in root canals and oral cavity of children and adults. In children, 4 oral cavity samples were positive and 4 samples also showed Candida in root canals. In adults , 1 sample each was positive for Candida in both root canals and oral cavity.

Table 8: Isolation frequency of Candida species in oral cavities of children and adults

\begin{tabular}{|c|c|c|c|c|c|c|}
\hline \multirow[t]{2}{*}{ Candida species } & \multicolumn{3}{|c|}{ CHILDREN } & \multicolumn{3}{|c|}{ ADULTS } \\
\hline & $\begin{array}{c}\text { Control } \\
n=25\end{array}$ & $\begin{array}{c}\text { Experimental } \\
n=25\end{array}$ & $\begin{array}{ll}\text { Total }_{50} & n=\end{array}$ & $\begin{array}{c}\text { Control } \\
n=25\end{array}$ & $\begin{array}{c}\text { Experimental } \\
n=25\end{array}$ & $\operatorname{Total}_{50} \mathrm{n}=$ \\
\hline C.albicans & $2(8 \%)$ & $3(12 \%)$ & 5 & 0 & $1(4 \%)$ & 1 \\
\hline C.tropicalis & 0 & $1(4 \%)$ & 1 & 0 & 0 & 0 \\
\hline C.krusei & 0 & 0 & 0 & 0 & 0 & 0 \\
\hline C.guillermondi & 0 & 0 & 0 & 0 & 0 & 0 \\
\hline Total positive cases & 2 & 4 & 6 & 1 & 1 & 2 \\
\hline
\end{tabular}

Table 8 shows the isolation frequency of common Candida species found in the oral cavities of children and adults in both experimental and control groups. In the control group of children, C.albicans (2 samples) was isolated. In the experimental group of children, 3 samples were positive for C. albicans and 1 sample was positive for C. tropicalis. Amongst adults, C.albicans ( 1 sample in experimental group) and C.parapsilosis (1 sample in control) were isolated. C.glabrata, C.dubiliniensis, C.krusei and C.guillermondi were not isolated from any of the samples. 
Evaluation of prevalence of Candida species in the root canals and oral cavity of children and....

Table 9: Isolation frequency of Candida species in root canals of children and adults

\begin{tabular}{|c|c|c|}
\hline Candida species & $\begin{array}{c}\text { CHILDREN } \\
\mathbf{n = 2 5}\end{array}$ & $\begin{array}{c}\text { ADULTS } \\
\mathbf{n = 2 5}\end{array}$ \\
\hline C.albicans & $3(12 \%)$ & $1(4 \%)$ \\
\hline C.glabrata & 0 & 0 \\
\hline C.tropicalis & $1(4 \%)$ & 0 \\
\hline C.krusei & 0 & 0 \\
\hline C.dubiliniensis & 0 & 0 \\
\hline C.parapsilosis & 0 & 0 \\
\hline C.guillermondi & 0 & 0 \\
\hline Total positive cases & 4 & 1 \\
\hline
\end{tabular}

Table 9 shows different Candida species that were isolated from root canals of children and adults. In children, C.albicans (3 samples) and C. tropicalis (1 sample) was isolated. In adults, only 1 sample of C. albicans was isolated from any of the samples.

\section{Discussion}

Candida species are ubiquitous yeasts and common residents of mucosal surfaces of the human oral cavity, gastrointestinal and urogenital tract. About $50 \%$ of the world population is colonized by Candida. Oral yeasts have been isolated from dental plaque, dental caries, subgingival flora and root canals and constitute only $1 \%$ of the total cultivable flora in most specimens. The study was done to evaluate the prevalence of Candida species in root canals and oral cavities of children and adults. The age group of 6-9 years for children was selected as in this age the children reporting with carious deciduous molars undergo endodontic treatment for maintainence of arch width to provide space for successor permanent tooth. Similar studies on prevalence of Candida species in age group of 6-8 years was done by Akdenz et al $(2002)^{11}$ and Kadir et al $(2005)^{12}$. The adults selected for this study were in the age group of 20-40 years i.e young to middle aged adults. The $\mathrm{pH}$ of saliva was found out to be in the range of 6-7. Similar findings were reported by Akdeniz et al (2002) ${ }^{11}$ who found insignificant relationship between carries and non-carries of C.albicans to salivary $\mathrm{pH}$. In present study, gender distribution of samples was 1.27:1 i.e 56 males and 44 females. 8 samples among males (16.07\%) and 4 samples of females $(9.09 \%)$ were positive. Ratio of occurrence of Candida species between males and females was 2.55:1. Difference in Candida occurrance between two sexes was statistically insignificant. This result was in accordance with study done by Berdicevsky et al (1984) $)^{13}$ who reported similar results. Samples were taken from the dorsum of tongue as Candida is most frequently found on this surface. Miranda et al (2009) ${ }^{14}$ stated that dorsum of the tongue is the primary habitat of yeasts in the mouth. In the present study, prevalence of oral candida in healthy children belonging to control group was $8 \%$ which is less than the prevalence rate in the studies done by Kadir et al $(2005)^{12}$ who reported a rate of $50.3 \%$. Similarly prevalence of Candida in oral cavities of adults belonging to control group was $4 \%$ which was again less as compared to study done by Kleinegger et al $(1996)^{15}$. This variation seen in the incidence of candida in oral cavity could be due to the physiological flushing action of saliva which curbs the growth of oral candidal populations. Some unrecognised salivary constituents in non-carriers may also impart damage to the cell membrane of Candida leading to reduced growth or cell debility and death. In present study, prevalence of oral Candida between two groups of children was not statistically significant (p-value 0.667) i.e. carious lesion does not increase the tendency of oral cavity to Candidal colonization in children. This is not in accordance with the study done by Akdeniz et al $(2002)^{11}$. A comparison of prevalence of Candida in oral cavities between experimental and control groups in adults showed a statistically non significant $p$ value of 1 . It indicates that the presence of carious lesion doesnot increase the tendency of oral cavity to Candidial colonization in adults. The prevalence rate of Candida in root canals of children was $4(16 \%)$. Akdeniz et al $(2002)^{11}$ reported a prevalence rate of $69.2 \%$ in root canals of children with caries. In adults with root canal, Candida was seen in $4 \%$ cases. Reported rates of yeast incidence in root canals vary widely from $0.5 \%$ to $55 \%$ as reported by Goldman \&Pearson. ${ }^{16}$

In present study, out of 50 samples collected from oral cavities of children, $6(12 \%)$ were positive for Candida. Out of these 6 positive samples, 5(83\%) were positive for Candida albicans , 2 samples were from control group and 3 from experimental group and 1(17\%) was positive for Candida tropicalis obtained from experimental group. These results were in accordance with the studies done by Kadir T et al $(2005)^{12}$ and Qi QG et al $(2005)^{17}$ who found C.albicans to be the most common isolates from oral cavity. In root canals samples of children, 3(12\%) samples showed C.albicans and 1(4\%) sample showed C.tropicalis. Qi QG et al $(2005)^{17}$ reported $76.7 \%$ isolates from oral cavity of children comprising of C.albicans and other species isolated were C.glabrata and C.tropicalis. Amongst oral cavity samples from 50 adult subjects, only 2 samples were positive for Candida i.e 1(4\%) sample from control group identified as Candida parapsilosis and 1(4\%) from experimental group identified as Candida albicans. Similar results were shown in studies done by Qi QG et al $(2005)^{17}$ and Zaremba ML et al $(2006)^{18}$. In root canal samples of adults, only $1(4 \%)$ tested positive for Candida 
which was identified as Candida tropicalis. Miranda TT et al (2009) ${ }^{14}$ reported isolation of C.parapsilosis (5.2\%) and C.tropicalis (1.3\%) from root canals of adults besides C.albicans which was the most common isolate. In present study, C.albicans was the most commonly isolated Candida species in oral cavity in children. This could be due to more adaptation of C.albicans than other species as oral commensal organism. Similar results were reported by Kleinegger et al $(1996)^{15}$. C.tropicalis was isolated from both oral cavity and root canals. This result was in accordance to study done by Miranda TT et al (2009) ${ }^{14}$ who reported C.tropicalis as the second most prevalent yeast isolated from oral cavity samples. Present study reported C.parapsilosis from oral cavity of one subject of adult control group.

\section{Conclusion}

The prevalence of Candida was low in oral cavities of both children and adults which may be due to variability in salivary flow rate, presence of Candidal antibodies and certain components of saliva such as amylase, lysozyme, bacterial glucosyl transferases, glucans, albumin, immunoglobulins and C3 fragments. Interplay of these fragments either promotes or inhibits yeast growth. Ratio of occurrence of Candida species between males and females was 2.55:1. Similar range of $\mathrm{pH}$ was observed in both Candida carriers and noncarriers. Candida isolation from children and adults had a similar frequency rate. Thus, difference in dentition and eating habits is less likely to influence the carriage rate of Candida. Candida albicans was found to be the most common isolated species of Candida from the oral cavity in children with or without caries. Hence, presence of carious lesion has no effect on Candidial colonization of oral cavity in both children and adults.

\section{References}

[1]. Sen BH, Safavi KE and Spangberg LSW, Colonization of Candida albicans on cleaned human dental hard tissues, Arch Oral Biol, 42(7), 1997, 513-520.

[2]. Ercan E, Dalli M, Yavuz I and Ozekinci T, Investigation of microorganisms in infected dental root canals, Biotechnol \& Biotechnol Eq,20(2),2006,166-172.

[3]. S. L. Zunt, Oral candidiasis: diagnosis and treatment, The Journal of Practical Hygiene, vol. 9, 2000, 31-36.

[4]. Tekeli A, Dolapci I, Emral R, Cesur S, Candida carriage and Candida dublinienis in oropharyngeal samples of type-1 diabetes mellitus patients, Mycoses, 47, 2004, 315-8.

[5]. Hazen KC, New and emerging yeast pathogens, Clin Microbiol Rev, 8, 1995, 462-78.

[6]. Ajello L and Hay RJ, Candida species and Blastoschizomyces capitatus, Topley and Wilson's Microbiology and Microbial infections-Medical Mycology 4, 1994, 423-456.

[7]. Siqueira Junior, SEN and B. H, Fungi in endodontic infections, Oral Surgery, Oral Medicine, Oral Pathology, Oral Radiology and Endodontics, 97(5),2004, 632-641.

[8]. Loesche W. J, Schork A, Terpenning M. S, Chen, Y. M, Factors which influence levels of selected organisms in saliva of older individuals, Journal of Clinical Microbiology, 33(10),1995,2550-2557.

[9]. Thylstrup A, How should we manage initial and secondary caries? Quintessence International, 29(9), 1998,594-598.

[10]. Adriane Castro Martinez Martins, Márcia Luzia Ferrarezi Maluf and Terezinha Inez Estivalet Svidzinski, Prevalence of yeast species in the oral cavity and its relationship to dental caries, Acta Scientiarum Health Sciences Maringá, 33(1),2011,107-112.

[11]. Akdeniz BG, Koparal E, Sen BH, Ates M and Denizci AA, Prevalence of Candida albicans in oral cavity and root canals of children, J Dent for children, 2002, 289-292.

[12]. Kadir T, Uygun B and Akyuz S, Prevalence of Candida species in Turkish children: Relationship between dietary intake and carriage,.Arch Oral Biol, 50, 2005 ,33-37.

[13]. Berdicevsky I, Ben-Aryeh H, Szargel R and Gutman D, Oral Candida in children, Oral Surgery, 57, 1984, 37-40.

[14]. Miranda TT, Vianna CR, Rodrigues L, Monteiro AS, Rosa CA and Correa Jr A, Diversity and frequency of yeasts from the dorsum of tongue and necrotic root canals associated with primary apical periodontitis, Int Endod J, 42, 2009,839-844.

[15]. Kleinegger CL, Shawn R Lockart, Kaaren Vargas and David R Soll, Frequency, Intensity, Species and Strains of Oral Candida vary as a function of host age, J Clin Microbiol, 34(9), 1996, 2246-2254.

[16]. Goldman M and Pearson AH, Post debridement bacterial flora and antibiotic sensitivity, Oral Surg Oral Med Oral Pathol, 28, 1969, 897-905.

[17]. Qi QG, Hu T and Zhou XD, Frequency, species and molecular characterization of oral Candida in hosts of different age in China, J Oral Pathol Med, 34, 2005, 352-6.

[18]. Zaremba ML et al, Incidence rate of Candida species in the oral cavity of middle aged and elderly subjects, Adv Med Sci, 51(1), 2006, 233-236. 